\title{
Nested PCR to detect and distinguish the sympatric filarial species Onchocerca volvulus, Mansonella ozzardi and Mansonella perstans in the Amazon Region
}

\author{
Thuy-Huong Ta Tang1, Rogelio López-Vélez ${ }^{3}$, Marta Lanza', Anthony John Shelley, \\ Jose Miguel Rubio', Sérgio Luiz Bessa Luz²/+

\begin{abstract}
'Malaria y Protozoos Emergentes, Servicio de Parasitología, Centro Nacional de Microbiología, Instituto de Salud Carlos III, Carretera ${ }^{3}$ Unidad de Medicina Tropical y Parasitología Clínica, Servicio de Enfermedades Infecciosas, Hospital Ramón y Cajal, Madrid, España ${ }^{4}$ Department of Entomology, Natural History Museum, London, United Kingdom
\end{abstract} \\ Majadahonda-Pozuelo km 2, 28220 Majadahonda, Madrid, España ${ }^{2}$ Instituto Leônidas e Maria Deane-Fiocruz Amazônia, Manaus, AM, Brasil
}

We present filaria-nested polymerase chain reaction (PCR), which is based on amplification of first internal transcribed spacer rDNA to distinguish three parasitic filarial species (Onchocerca volvulus, Mansonella ozzardi and Mansonella perstans) that can be found in the Amazon Region. Nested PCR-based identifications yielded the same results as those utilizing morphological characters. Nested PCR is highly sensitive and specific and it detects low-level infections in both humans and vectors. No cross-amplifications were observed with various other blood parasites and no false-positive results were obtained with the nested PCR. The method works efficiently with wholeblood, blood-spot and skin biopsy samples. Our method may thus be suitable for assessing the efficacy of filaria control programmes in Amazonia by recording parasite infections in both the human host and the vector. By specifically differentiating the major sympatric species of filaria, this technique could also enhance epidemiological research in the region.

Key words: nested PCR - 18S rDNA - ITS-1 - onchocerciasis - mansonelliasis - Brazil

The phylum Nematoda contains the filarial round worms of the superfamily Filarioidea, which parasitize humans as well as animals. Human filariae are vectorborne and are responsible for various diseases, including human onchocerciasis (Onchocerca volvulus), lymphatic filariasis (Brugia malayi, Brugia timori and Wuchereria bancrofti), loaiasis (Loa loa) and mansonelliasis (Mansonella perstans, Mansonella ozzardi and Mansonella streptocerca) (Morales-Hojas 2009). In Brazil, four out of the preceding eight filarial species occur: $O$. volvulus (Bearzoti et al. 1967), M. ozzardi (Rachou et al. 1954, Moraes et al. 1983), W. bancrofti (Causey et al. 1945) and M. perstans (Orihel 1967, Kozek et al. 1983, Formica \& Botto 1990). Of these, only O. volvulus and $M$. ozzardi significantly affect humans. In Brazil, O. volvulus is found in the northwestern state of Roraima (RR) and in the northern state of Amazonas (AM), where it mainly affects Yanomami Indians (Shelley 2002), but another focus of the disease has been described in Central-western Brazil (Maia-Herzog et al. 1999). The less pathogenic $M$. ozzardi occurs mainly in AM, south of the Amazon River, and in an area in northern RR;

Financial support: Spanish Ministry of Science and Innovation (PET2007 217), CNPq (483810/2007-0)

+Corresponding author: sergioluz@amazonia.fiocruz.br

Received 5 April 2010

Accepted 22 July 2010 it occurs sympatrically with $O$. volvulus in some areas within the Amazonian onchocerciasis focus (Shelley 2002, Medeiros et al. 2009). Following several years of control programmes, $W$. bancrofti is now uncommon and is restricted to urban and peri-urban areas of Belém and Recife, with some cases of autochthonous transmission in neighboring states (Medeiros et al. 2003). It is also possible that $M$. perstans is present in the Brazilian Amazon because it occurs sympatrically with $M . o z$ zardi in the neighboring regions of southern Colombia (Kozek et al. 1983), western Guyana (Orihel 1967) and Venezuela (Formica \& Botto 1990). Accurate identification is, therefore, essential in studies on $O$. volvulus, $M$. ozzardi and M. perstans epidemiology and transmission in Brazil and circumjacent countries.

Nematode species are frequently identified and distinguished on the basis of morphological features, the hosts that they infect, their transmission patterns, their pathological effect on the hosts and their geographical origin (Gasser 2006). Diagnosis and epidemiological surveys are traditionally based on the identification of microfilariae in thick blood films or in preparations from skin biopsies. However, these techniques are labor intensive, not always accurate, tedious, time consuming and often impractical. Furthermore, these approaches require skilled microscopists to distinguish species of microfilariae that may coexist in one region, colonize the same tissues and be transmitted by the same vector (Walther \& Muller 2003). In Brazil, and especially in Amazonia, atypical filarial localizations in the human host make microscopic diagnosis complicated. Thus, $O$. volvulus microfilariae, generally present in the skin, 
have been detected in blood samples (Fuglsang \& Anderson 1974, Duke et al. 1975) and M. ozzardi microfilariae have been found in skin, although they are generally found in peripheral blood (Ewert et al. 1981, Moraes et al. 1983). The traditional approach of one filarial species being transmitted by a single genus of diptera fly that will then provide clues for the classification of additional filarial species no longer holds. Both M. ozzardi and O. volvulus are transmitted by blackflies (Simuliidae) in the Brazilian Amazon (Shelley 2002). In Brazil, M. ozzardi is carried by flies from the genus Simulium, the same vector utilized by $O$. volvulus, while in Latin America, M. ozzardi is generally transmitted through the bite of Culicoides (Shelley \& Coscarón 2001). The parasite is the same species, since nuclear ribosomal DNA sequences from simuliid-transmitted populations of M. ozzardi in Brazil and from simuliid and Culicoides-transmitted populations in Argentina were the same (Morales-Hojas et al. 2001).

Identification of M. ozzardi, M. perstans and O. volvulus is straightforward when individuals are in the adult stage. However, only adult $O$. volvulus are easy to find in superficial skin nodules. Adult M. ozzardi and M. perstans are more difficult to locate because of their presence internally in the mesentery. Therefore, it is customary to base routine identification on the larval form in humans, the microfilaria. Microfilariae are morphologically distinguishable by the position within the body of the constituent nuclei (Sasa 1976, Post et al. 2003). The detection of filarial larvae in vectors is also based on conventional dissection techniques and morphological criteria for identifying filarial stages and for distinguishing species. Identification of filarial species in Brazil is only possible when organisms are in the microfilarial and infective larval stages; L1 and L2 larvae, those most commonly encountered, cannot be identified.

In order to overcome the limitations of conventional microscopic diagnosis for filarial species identification, other methods such as serodiagnosis and antigen detection have been used with varying levels of success (Vincent et al. 2000, Ramzy 2002, Molyneux 2009). The use of an enzyme linked immunosorbent assay test for identifying $O$. volvulus failed in Brazil because of crossreactivity between this species and M. ozzardi (Shelley et al. 2001). Nucleic acid techniques provide powerful tools for the diagnosis of several parasitological diseases including malaria, leishmaniasis and Chagas disease. Strategically, the polymerase chain reaction (PCR) approach fulfils several objectives related to the diagnosis of filariasis in the human host and the detection of filarial larvae in the vector because it can detect a single worm and is cost effective (Ramzy 2002). Several PCR methods have been described for the specific diagnosis of filariasis, most of which use repetitive DNA, including ribosomal genes, to detect $M$. streptocerca (Fischer et al. 1998) or O. volvulus and M. ozzardi in Brazil (Morales-Hojas et al. 2001); specific nematode genes, such as Major Sperm Protein, have also been used (Hojas \& Post 2000, Walther \& Muller 2003, Gasser 2006).

The method developed for $O$. volvulus, based on the amplification of a repetitive sequence of 150 nucleotides (designated O-150) by PCR, demonstrated cross-reac- tivity with other filarial species; thus, a species-specific probe was required for diagnosis (Meredith et al. 1991, Zimmerman et al. 1994, Maia-Herzog et al. 1999).

Only a small subset of methods is able to differentiate several nematodes in the same PCR reaction, generally after enzymatic digestion (Nuchprayoon et al. 2005).

The objective of this work is to provide an accurate molecular identification method that is able to characterize the three human sympatric filariae known to inhabit the Amazon Region of Brazil and neighboring countries, using a specific and sensitive nested PCR. The method could be used in the different filarial control programmes carried out in the Amazon Region of Brazil. This PCR is designed to amplify the internal transcriber spacers of the ribosomal gene of filarial species. The size of this region varies among $O$. volvulus, $M$. ozzardi and $M$. perstans and it is expected to yield amplicons of different sizes for each species.

\section{SUBJECTS, MATERIALS AND METHODS}

$O$. volvulus was isolated from skin biopsies from two patients from RR, Brazil. M. ozzardi was obtained as dried blood-spots on Whatman filter paper from five patients identified by microscopic examination in RR, Brazil. M. perstans was isolated from whole blood of African patients attending the Tropical Medicine and Clinical Parasitology Unit of Hospital Ramón y Cajal, Madrid, Spain and was diagnosed microscopically after concentration.

Amplification controls included Loa loa and W. bancrofti, which were isolated, respectively, from an Equatorial Guinean patient and a Brazilian patient. Furthermore, filariae-negative samples that were known to be positive or negative for other tropical parasites, such as Plasmodium spp, were used as negative controls, together with five microscopically negative samples obtained in the same collection as the M. ozzardi-positive samples.

In summary, the study was carried out on two skin biopsies (RR), 12 dried blood-spots on filter paper (RR) and 10 whole-blood samples of African origin [Hospital Ramón y Cajal and Instituto de Salud Carlos III (ISCIII)] with several filariae-negative samples used as negative controls.

Brazilian samples were obtained as part of a study approved by the Research Ethical Committee of the Amazon Hematology and Hemotherapy Foundation, Brazil (CAAE-0001/2006). African samples were taken from the Repository Unit of the Malaria and Emerging Parasitic Diseases Laboratory of the ISCIII.

DNA extraction - DNA extraction from the whole blood samples $(200 \mu \mathrm{L})$ was performed with the QIAamp ${ }^{\circledR}$ DNA mini kit (QIAGEN), according to the manufacturer's instructions. Dried blood-spots on filter paper were processed using the Chelex method (Rubio et al. 2002).

Primer design - Four PCR primers were designed by comparison with published ribosomal gene sequences with at least partial sequences for $18 \mathrm{~S}$ (small subunit ribosomal RNA), ITS-1 (first internal transcribed spacer), 5.8S and ITS-2. The following species with different sequences were compared (EMBL GenBank accession indicated in parentheses): $O$. volvulus (AF228575, AF228574, 
TABLE I

List of polimerase chain reaction (PCR) primers used in the study

\begin{tabular}{lcccc}
\hline Primer & Sequence 5'-3' & Specificity & $\begin{array}{c}\text { Position in reference } \\
\text { sequence (gene) }\end{array}$ & Size of PCR product \\
\hline UNI-1R & CGCAGCTAGCTGCGTTCTTCATCG & Universal & AF228575: 631 (5.8S) & $712-771^{a}$ \\
FIL-1F & GTGCTGTAACCATTACCGAAAGG & Filarias & AF227234: 1446 (18S) & \\
FIL-2F & GGTGAACCTGCGGAAGGATC & Filarias & AF228575: 173 (18S) & $286-344^{b}$ \\
FIL-2R & TGCTTATTAAGTCTACTTAA & Filarias & AF228575: 493 (ITS1) & \\
\hline
\end{tabular}

a: size depending upon species (Onchocerca volvulus: 771 bp, Mansonella perstans: 739 bp, Mansonella ozzardi: 734 bp, Wuchereria bancrofti: 723 bp, Loa loa: 712 bp); b: size depending upon species (O. volvulus: 344 bp, M. perstans: 312 bp, M. ozzardi: 305 bp, W. bancrofti: 301 bp, Loa loa: 286 bp).

AF228565), M. ozzardi (AF228564, AF228560), $W$. bancrofti (AY621478, AY621477, AY843438, AY843437, AY843436, AF227234), B. malayi (AY621468, AY621465, AY499507, AF499130, AF036588, AF499130), B. timori (AF499132), Dirofilaria immitis (AF217800, AF036638, AF182647) and various human and mouse sequences.

The sequences were aligned using CLUSTALW (Thompson et al. 1994) and the primer selection was based on general primer design criteria, including, where possible, $\mathrm{Tm}=60^{\circ} \mathrm{C}$, at least $40 \%$ guanine-cytosine content and less than $60 \%$ homology with non-filarial species for the family-specific primers.

Sequence specificity and location (with respect to the GenBank sequence used as reference) of the designed primers is shown in Table I. A reverse primer (UNI-1R) was designed that would hybridize universally to all filarial species and a wide range of vertebrates, including mammals. There were two forward and one reverse primer(s) that hybridized to all filarial species (FIL-1F, FIL-2F and FIL-2R).

The primer concentrations for both reactions were determined empirically. The best primer concentrations were those where all the templates, including single and double infections, were perfectly amplified.

Filariae detection and identification - Filariae detection and species identification relied on a sequence of two PCRs (nested PCR), with the size of products estimated by an automatic capillary electrophoresis system (QIAxcel, BioRad) or by agarose gel electrophoresis with ethidium bromide staining in a Gel Doc 2000 (BioRad).

The first reaction incorporates primers FIL-1F and UNI-1R and was expected to yield a product between 712$771 \mathrm{bp}$, depending on the species (Table I). This fragment is only visible when either the number of microfilariae in the sample or the DNA concentration is high.

The second PCR incorporates the products of the first reaction together with the primers FIL-2F and FIL-2R. Infection with different species of filarial species yielded products of different sizes. A band of 344 bp indicates infection with $O$. volvulus, one of $312 \mathrm{bp}$ indicates $M$. perstans and one of 305 bp indicates $M$. ozzardi. Other theoretical amplified fragment sizes correspond to the following genus/species of the family:

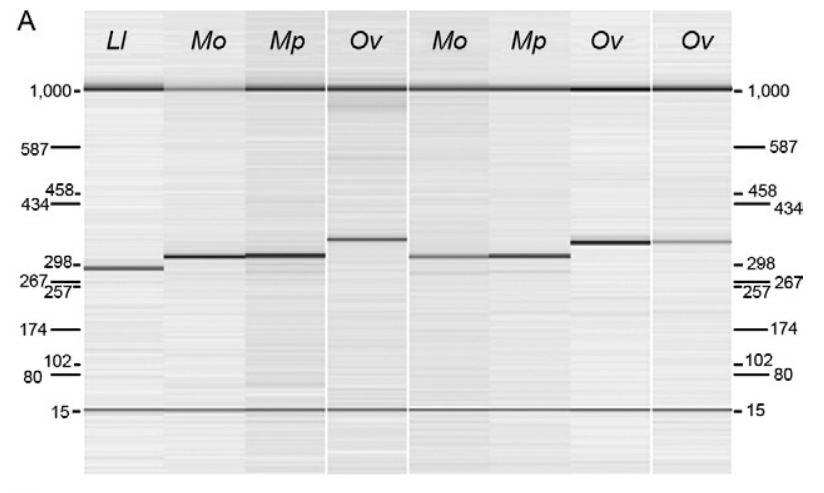

B

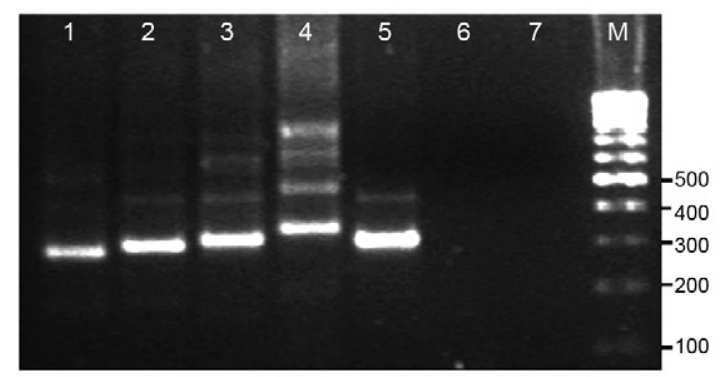

Nested polymerase chain reaction amplification products. A: gel representation of QIAxcel capillary electrophoresis (Ll: Loa loa, Mo: Mansonella ozzardi, Mp: Mansonella perstans, Ov: Onchocerca volvulus); B: agarose gel. Line 1: Loa loa; 2: Wuchereria bancrofti; 3: M. perstans; 4: O. volvulus; 5: M. ozzardi; 6: negative filaria sample; 7: no DNA; M: size marker $100 \mathrm{bp}$.

$301 \mathrm{bp}$ indicates $W$. bancrofti and 286 bp indicates Loa loa (Table I). W. bancrofti and the Mansonella sp. yield fragments of similar sizes. In practice, $W$. bancrofti is not difficult to distinguish in a $2.5 \%$ agarose gel. However, the difference between M. perstans and M. ozzardi is more complicated to resolve and requires the use of more sophisticated equipment or sequencing (Figure).

The PCR mixture in both reactions consisted of $75 \mathrm{mM}$ Tris $\mathrm{HCl}(\mathrm{pH} 9.0), 2 \mathrm{mM} \mathrm{MgCl}, 50 \mathrm{mM} \mathrm{KCl}$, $20 \mathrm{mM}\left(\mathrm{NH}_{4}\right){ }_{2} \mathrm{SO}_{4}, 200 \mu \mathrm{M}$ dNTP, PCR primers, 1.25 units of Taq DNA polymerase (Biotools B\&M Labs, 
TABLE II

List of sequences submitted to the GenBank data base

\begin{tabular}{lccc}
\hline Species & Isolate & Country & Accession \\
\hline Onchocerca volvulus & Ov1/07 & Brazil & EU272179 \\
Mansonella ozzardi & $\mathrm{Mo1} / 07$ & Brazil & EU272180 \\
Mansonella perstans & $\mathrm{Mp} 4 / 07$ & Cameroon & EU272183 \\
M. perstans & $\mathrm{Mp} 1 / 07$ & Sierra Leone & EU272177 \\
$M$. perstans & $\mathrm{Mp} 2 / 07$ & Mali & EU272181 \\
M. perstans & $\mathrm{Mp} 3 / 07$ & Equatorial Guinea & EU272182 \\
M. perstans & $\mathrm{Mp} 5 / 07$ & Equatorial Guinea & EU272184 \\
Wuchereria bancrofti & $\mathrm{Wb1} / 07$ & Brazil & EU272178 \\
Loa loa & $\mathrm{Lloa} 1 / 07$ & Equatorial Guinea & EU272176 \\
\hline
\end{tabular}

Madrid, Spain) and template DNA in a reaction volume of $50 \mu \mathrm{L}$. The amount of template was $5 \mu \mathrm{L}$ of DNA, extracted by QIAgen. For the second reaction mixture, the template used was $2 \mu \mathrm{L}$ of the PCR product of the first reaction. For both reactions, a GeneAmp ${ }^{\circledR}$ PCR System 2700 thermal cycler (Applied Biosystems Laboratory) was used, beginning with $7 \mathrm{~min}$ at $94^{\circ} \mathrm{C}$, followed by (first-round) 40 cycles of $20 \mathrm{~s}$ at $94^{\circ} \mathrm{C}, 20 \mathrm{~s}$ at $60^{\circ} \mathrm{C}$ and $30 \mathrm{~s}$ at $72^{\circ} \mathrm{C}$, or (second-round) 35 cycles of $20 \mathrm{~s}$ at $94^{\circ} \mathrm{C}$, $20 \mathrm{~s}$ at $50^{\circ} \mathrm{C}$ and $20 \mathrm{~s}$ at $72^{\circ} \mathrm{C}$. The final cycle was followed by an extension time of $10 \mathrm{~min}$ at $72^{\circ} \mathrm{C}$.

Sequencing - The amplified products were purified using Illustra DNA and Gel Band Purification Kit (General Electric Healthcare), then sequenced using Big Dye Terminator v3.1 Cycle Sequencing in an ABI PRISM ${ }^{\circledR}$ 3700 DNA Analyzer. All amplified products were sequenced in both directions, twice.

Specific Loa loa amplification - In order to specifically detect Loa loa in the samples, nested PCR developed by Touré et al. (1999) was used.

\section{RESULTS}

Filarial 18S-ITS1-5.8S rDNA sequences were aligned in order to design filariae-specific primers and the annealing regions were chosen to maximize the interspecific differences while minimising intraspecific variation. Four primers were designed: two specific filaria forward primers, FIL-1F and FIL-2F, in the 5'-end region of the $18 \mathrm{~S}$ gene; one universal reverse primer (UNI$1 \mathrm{R})$ in the $5.8 \mathrm{~S}$ ribosomal gene and one filaria-specific reverse primer (FIL-2R) in the ITS-1 zone.

The sizes of PCR products obtained after the second amplification with FIL-2F and FIL-2R primers for each filaria species corresponded closely to the expected size. The two skin biopsies yielded fragments of approximately $344 \mathrm{bp}$. Of the 12 blood-spot samples, five yielded a $305 \mathrm{bp}$ fragment (corresponding to M. ozzardi) and two yielded a $301 \mathrm{bp}$ fragment (corresponding to $W$. bancrofti), with no amplification in the five negative samples. For all cases, the results obtained on the blood-spot samples were as expected. Of the 10 positive whole-blood samples, seven yielded 312 bp fragments (corresponding to $M$. perstans) and three yielded $286 \mathrm{bp}$ fragments (Loa loa). These results confirmed the data obtained by microscopy, except in one case where Loa loa infection was expected and the PCR yielded a 312 bp fragment corresponding to $M$. perstans. This sample was processed, together with other Loa loa-positive infections, with a specific PCR for Loa loa (Touré et al. 1999). The sample showed no amplification while the rest of the positive samples yielded fragments of $360 \mathrm{bp}$, which corresponded to the size of the expected fragment. The filaria PCR method was also tested on negative samples and samples infected with other parasites and there was no evidence of false-positive results.

All amplified fragments from the naturally infected samples were sequenced to confirm the nucleotide sequence and the size of the fragment. In all cases, the nucleotide sequence number of the amplified fragment corresponded to the expected size and the sequence with maximum homology corresponded to the appropriate filarial species. Sequences with some variations in nucleotide sequence or epidemiological data have been submitted to the GenBank database (Table II).

In order to determine the sensitivity of the technique, serial dilutions of the positive DNAs were tested. In the case of Onchocerca DNA, which were the only samples where DNA without human contamination was measured (38.7 and $50 \mathrm{ng} / \mu \mathrm{L}$ in each, respectively), the method amplified down to 0.003 and $0.005 \mathrm{ng} / \mu \mathrm{L}$, respectively, which corresponds to less than a microfilaria worm (Leroy et al. 2003). When positive whole-blood samples were serially diluted, these allowed positive amplification up to 100 -fold dilutions, indicating that the method is able to characterize the filaria species at very low parasite levels.

\section{DISCUSSION}

It is difficult to assess the accuracy of the method described because any meaningful evaluation must be made with natural infections and inevitably involves comparison with other methods of diagnosis, which might be wrong. All the control and naturally infected 
samples yielded the expected result for the three Amazonian filariae, O. volvulus, M. ozzardi and M. perstans. Likewise, the samples infected with $W$. bancrofti and Loa loa yielded the expected result, except in one sample where one discrepancy occurred. A microscopically diagnosed Loa loa infection was characterized as M. perstans by the fragment size (312 bp) obtained using the filaria PCR method. All the samples uninfected with filariae were negative, showing no evidence of falsepositive results. It is therefore likely that the field sample that yielded M. perstans when filaria PCR was used to identify what had previously been labeled after morphological examination as Loa loa was actually M. perstans. Also, this sample did not show amplification when a specific Loa loa nested PCR was performed (Touré et al. 1999), again suggesting that the microscopic identification of Loa loa was incorrect. There remains the possibility of cross-contamination, but several measures to avoid it were taken (Rubio et al. 2002). Another possibility is that there was a mixed infection in the sample and that the PCR methods were unable to detect both parasites simultaneously, perhaps because the presence of a second filaria inhibits the amplification reaction in the filaria and Loa loa nested PCRs, while the microscopist was able to identify the more prevalent pathogen in the sample. The PCR method carried out with mixed control infection samples shows the appropriate fragment size amplifications in all different tested combinations. Furthermore, the sensitivity of the method seems to be very high. All these facts suggest a misdiagnosis in the microscopy, as this diagnostic method is highly subjective, requires considerable expertise and has limited sensitivity (Walther \& Muller 2003).

The specificity test for the filaria PCR revealed that no cross-amplification occurred for any blood parasite other than those commonly found in humans.

The filaria PCR developed has a high level of sensitivity and specificity, is able to distinguish specifically between different filarial species and is suitable for detection of low-parasitemia samples. Filaria PCR could, therefore, be useful for the detection of carriers and as a tool to follow drug treatment. Moreover, the PCR methods have the advantage that no fresh samples are needed to make a correct diagnosis, as the DNA from damaged parasites in skin biopsies or peripheral blood is detectable for years by PCR, while the morphology is generally lost. The filaria PCR described here works well irrespective of the source sample, including whole blood, head nodules, blood-spots and skin biopsies.

Furthermore, filaria PCR serves a special function in the differential detection of filariae in situations where species are co-endemic. The coexistence of different species of filariae in the same individual in Amazonia has the same important epidemiological implications as in Africa (Wanji et al. 2003). In Brazil, where O. volvulus and $M$. ozzardi are sympatric, misidentifications and errors have already been reported (Ewert et al. 1981, Moraes et al. 1983, Morales-Hojas et al. 2001). The method previously described can only distinguish $M$. ozzardi from O. volvulus (Morales-Hojas et al. 2001) and a negative result does not discount the presence of a mixed infection in peripheral blood. Our new method will also be helpful in other regions where onchocerciasis is a problem, such as West Africa, where O. volvulus, M. perstans and $M$. streptocerca coexist. Moreover, as the primers were designed from highly conserved regions of filarial 18S, 5.8S rDNA and ITS1, the method will amplify not only $O$. volvulus, M. ozzardi and M. perstans, the main objective of our study, but also amplify the sequences from other filarial parasites, including human and zoonotic filarial nematodes such as $W$. bancrofti, B. malayi, B. timori, Loa loa, M. streptocerca and Dirofilaria sp. The ITS-1 area, where FIL-2R is designed, is highly conserved among filarial species and represents a region that is important for correct transcription and gene splicing.

Unlike the PCR-RFLP method developed by Nuchprayoon et al. (2005), our assay does not digest the PCR product with restriction endonucleases and increases sensitivity using a nested amplification.

Filaria PCR is a useful method for the detection of species-specific sequences. The method can detect any form and any stage of the life-cycle of filariae in the human host or the vector and is able to specifically differentiate the sympatric filariae present in the Amazon. It may thus become a useful tool to monitor disease in campaigns seeking to control filariasis in Brazil. Finally, our method requires only conventional PCR equipment that is already available in many endemic countries, in contrast to more sophisticated technologies, such as real-time PCR.

\section{ACKNOWLEDGEMENTS}

To the staff of Instituto Leônidas e Maria Deane, for their assistance throughout the project collecting and preparing blood samples in field and laboratory work.

\section{REFERENCES}

Bearzoti P, Lane E, Menezes Jr 1967. Relato de um caso de oncocercose adquirida no Brasil. Rev Paul Med 70: 102.

Causey OR, Deane MP, Costa O, Deane LM 1945. Studies on the incidence and transmission of filaria Wuchereria bancrofti in Belém, Brazil. Am J Hyg 41: 143-149.

Duke BO, Moore PJ, Vincelette J 1975. Factors influencing the passage of Onchocerca volvulus microfilariae into the urine. Tropenmed Parasitol 26: 449-468.

Ewert A, Smith JH, Corredor A 1981. Microfilariae of Mansonella ozzardi in human skin biopsies. Am J Trop Med Hyg 30: 988-991.

Fischer P, Büttner DW, Bamuhiiga J, Williams SA 1998. Detection of the filarial parasite Mansonella streptocerca in skin biopsies by a nested polymerase chain reaction-based assay. Am J Trop Med Hyg 58: 816-820.

Formica S, Botto C 1990. Filariasis focus due to Mansonella ozzardi and Mansonella perstans in the Amazon Federal Territory of Venezuela. J Trop Med Hyg 93: 160-165.

Fuglsang H, Anderson J 1974. Microfilariae of Onchocerca volvulus in blood and urine before, during and after treatment with diethylcarbamazine. J Helminthol 48: 93-97.

Gasser RB 2006. Molecular technologies in parasitology, with an emphasis on genomic approaches for investigating parasitic nematodes. Parassitologia 48: 9-11. 
Hojas RM, Post RJ 2000. Regional genetic variation in the major sperm protein genes of Onchocerca volvulus and Mansonella ozzardi (Nematoda: Filarioidea). Int J Parasitol 30: 1459-1465.

Kozek WJ, Palma G, Henao A, García H, Hoyos M 1983. Filariasis in Colombia: prevalence and distribution of Mansonella ozzardi and Mansonella (= Dipetalonema) perstans infections in the Comisaría del Guainía. Am J Trop Med Hyg 32: 379-384.

Leroy S, Duperray C, Morand S 2003. Flow cytometry for parasite nematode genome size measurement. Mol Biochem Parasitol 128: $91-93$.

Maia-Herzog M, Shelley AJ, Bradley JE, Luna Dias AP, Calvão RH, Lowry C, Camargo M, Rubio JM, Post RJ, Coelho GE 1999. Discovery of a new focus of human onchocerciasis in central Brazil. Trans R Soc Trop Med Hyg 93: 235-239.

Medeiros JF, Py-Daniel V, Barbosa UC, Izzo TJ 2009. Mansonella ozzardi in Brazil: prevalence of infection in riverine communities in the Purus region, in the state of Amazonas. Mem Inst Oswaldo Cruz 104: 74-80.

Medeiros Z, Menezes JA, Cesse EP, Lessa F 2003. Controle da filariose linfática no Brasil, 1951-2000. Epidemiol Serv Saude 12: 77-86.

Meredith SE, Lando G, Gbakima AA, Zimmerman PA, Unnasch TR 1991. Onchocerca volvulus: application of the polymerase chain reaction to identification and strain differentiation of the parasite. Exp Parasitol 73: 335-344.

Molyneux DH 2009. Filaria control and elimination: diagnostic, monitoring and surveillance needs. Trans R Soc Trop Med Hyg 103: 338-341

Moraes MA, Shelley AJ, Dias AP, Silva CJ 1983. The concentration of Mansonella ozzardi microfilariae in skin capillaries. Trans $R$ Soc Trop Med Hyg 77: 463-466.

Morales-Hojas R 2009. Molecular systematics of filarial parasites, with an emphasis on groups of medical and veterinary importance and its relevance for epidemiology. Infect Genet Evol 9: 748-759.

Morales-Hojas R, Post RJ, Shelley AJ, Maia-Herzog M, Coscarón S, Cheke RA 2001. Characterisation of nuclear ribosomal DNA sequences from Onchocerca volvulus and Mansonella ozzardi (Nematoda: Filarioidea) and development of a PCR-based method for their detection in skin biopsies. Int J Parasitol 31: 169-177.

Nuchprayoon S, Junpee A, Poovorawan Y, Scott AL 2005. Detection and differentiation of filarial parasites by universal primers and polymerase chain reaction-restriction fragment length polymorphism analysis. Am J Trop Med Hyg 73: 895-900.

Orihel TC 1967. Infections with Dipetalonema perstans and Mansonella ozzardi in the aboriginal Indians of Guyana. Am J Trop Med Hyg 16: 628-635.

Post RJ, Adams Z, Shelley AJ, Maia-Herzog M, Luna Dias AP,
Coscarón S 2003. The morphological discrimination of microfilariae of Onchocerca volvulus from Mansonella ozzardi. Parasitology 127: 21-27.

Rachou RG, Azambuja CE, Souza PS 1954. Length and width of microfilaria of Mansonella ozzardi and Wuchereria bancrofti in Brazil. Rev Bras Malariol Doencas Trop 6: 419-427.

Ramzy RM 2002. Recent advances in molecular diagnostic techniques for human lymphatic filariasis and their use in epidemiological research. Trans R Soc Trop Med Hyg 96 (Suppl. 1): 225-229.

Rubio JM, Post RJ, van Leeuwen WM, Henry MC, Lindergard G, Hommel M 2002. Alternative polymerase chain reaction method to identify Plasmodium species in human blood samples: the semi-nested multiplex malaria PCR (SnM-PCR). Trans $R$ Soc Trop Med Hyg 96 (Suppl. 1): 199-204.

Sasa M 1976. Human filariasis. A global survey of epidemiology and control, University Park Press, Baltimore, 819 pp.

Shelley AJ 2002. Human onchocerciasis in Brazil: an overview. Cad Saude Publica 18: 1167-1177.

Shelley AJ, Coscarón S 2001. Simuliid blackflies (Diptera: Simuliidae) and Ceratopogonid midges (Diptera: Ceratopogonidae) as vectors of Mansonella ozzardi (Nematoda: Onchocercidae) in northern Argentina. Mem Inst Oswaldo Cruz 96: 451-458.

Shelley AJ, Maia-Herzog M, Calvão-Brito R 2001. The specificity of an ELISA for detection of Onchocerca volvulus in Brazil in an area endemic for Mansonella ozzardi. Trans $R$ Soc Trop Med Hyg 95: 171-173.

Thompson JD, Higgins DG, Gibson TJ 1994. CLUSTAL W: improving the sensitivity of progressive multiple sequence alignment through sequence weighting, position-specific gap penalties and weight matrix choice. Nucleic Acids Res 22: 4673-4680.

Touré FS, Mavoungou E, Deloron P, Egwang TG 1999. Comparative analysis of 2 diagnostic methods of human loiasis: IgG4 serology and nested PCR. Bull Soc Pathol Exot 92: 167-170.

Vincent JA, Lustigman S, Zhang S, Weil GJ 2000. A comparison of newer tests for the diagnosis of onchocerciasis. Ann Trop Med Parasitol 94: 253-258.

Walther M, Muller R 2003. Diagnosis of human filariases (except onchocerciasis). Adv Parasitol 53: 149-193.

Wanji S, Tendongfor N, Esum M, Ndindeng S, Enyong P 2003. Epidemiology of concomitant infections due to Loa loa, Mansonella perstans, and Onchocerca volvulus in rain forest villages of Cameroon. Med Microbiol Immunol 192: 15-21.

Zimmerman PA, Guderian RH, Aruajo E, Elson L, Phadke P, Kubofcik J, Nutman TB 1994. Polymerase chain reaction-based diagnosis of Onchocerca volvulus infection: improved detection of patients with onchocerciasis. J Infect Dis 169: 686-689. 